\title{
Fatigue Design of Mooring Lines of Floating Type Combined Renewable Energy Platforms ${ }^{\dagger}$
}

\author{
Joonmo Choung $^{1 *}$, Sang-Ik Jeon ${ }^{1}$, Min-Seong Lee ${ }^{1}$ \\ ${ }^{1}$ Department of Naval Architecture and Ocean Engineering, Inha University, 253 Yonghyun-dong, Nam-gu, Incheon, Republic of \\ Korea, 402-751
}

(Manuscript Received June 7, 2011; Revised July 1, 2011; Accepted July 27, 2011)

\begin{abstract}
This paper presents the concept design procedure of a floating-type combined renewable energy platform based on hydrodynamic analyses and is focused on the fatigue design of taut-type mooring lines of the platform. Two types of combined renewable energy platforms are considered: a combination of wind turbine, wave turbine and photovoltaic energy plant and a combination of wind turbine, current turbine and photovoltaic energy plant. The basic configurations are conceptually determined from the understanding of floating offshore plants, while the main dimensions have been determined based on a hydrostatic calculation. Fully coupled hydrodynamic analyses have been carried out to identify the motion characteristics of the floating body and the tension histories of the mooring lines. The tension history is used for the fatigue life prediction based on the rain-flow cycle counting method. For the fatigue life prediction, tension life curves from API and the Palmgren-Miner rule are employed.
\end{abstract}

Keywords: Floating-type combined renewable energy platform, Line tension, RAO, Fatigue damage, rain-flow cycle counting, T-N curve

\section{Introduction}

It is known that due to the use of fossil energy, greenhouse gasses have been elevating the world average temperature. According to special report on emission scenarios (SRES) of the IPCC (Intergovernmental Panel on Climate Change), it is predicted that the carbon dioxide increase of the world's greenhouse gasses will reach $25 \sim 90 \%$ by 2030. Countries around the world have begun to recognize that climate change is a very serious problem and are looking for alternative energy resources.

Ocean renewable energy is considered as one of the substitutes for oil and gas. Many types of ocean renewable energies are available. For example,

\footnotetext{
†This paper was presented at the TEAM2011 conference, Incheon, Korea, September 2011.

* Corresponding author. Tel.: +82-32-860-7346

E-mail address: jmchoung@inha.ac.kr

Copyright (C) KSOE 2011.
}

wind, wave, current, and thermal difference are recognized as outstanding energy resources with respect to economic feasibility. The technology level utilizing each energy resource can be higher or lower according to the type of ocean renewable energy. The technology level is closely related to the commercial and economic feasibility of the energy resource.

It is believed that wind energy in ocean space is one of the most competitive ocean energies, because the electricity generation cost per kilowatt is the least expensive among all the renewable energies. Wind energy, in general, is the most efficient energy in the world, but the variations of wind speed and wind direction make it difficult to produce a constant generation of energy and to maintain the turbine structures. Wind speed variation is usually called wind turbulence, against which blade pitch and nacelle yaw systems are required. In the case of current energy turbine, there are many 
promising places in Korea where the average current velocity is more than $3 \mathrm{~m} / \mathrm{s}$ during tidal movement. It is expected that current energy generation is the most eco-friendly, predictable, and sustainable energy among other types of offshore renewables. It is known that the wave energy turbine is relatively eco-friendly, but it is difficult to obtain constant energy generation. The wave energy turbine should directly withstand harsh climatic conditions such as typhoons and cyclones. In the case of offshore photovoltaic energy, periodic generation is possible and the environmental restrictions are less limited than those of other renewables. The corrosion protective facility required may elevate construction cost and require high maintenance cost.

Major Korean shipyards have accumulated ocean engineering technologies of floating type marine structures such as commercial vessels and largesized FPSOs. Ship and offshore plant technologies can be directly applied to the design of offshore floating platforms with mounted wind, current, and wave turbines. Kim and Hong [1] presented the concept design of the floating-type combined renewable energy platform through investigating the demand analyses and ocean energy density of each ocean energy type. Ko et al. [2] proposed a concept idea for the floating energy island with a mounted current turbine, wave turbine, and water temperature plant. There are a number of deficiencies in the selection of the appropriate wave loads and the hydrodynamic analysis and fatigue analysis of the mooring system. The floating-type combined renewable energy plant was the first to be conceptually designed. Hong [3] intensively studied the development of the design technology of very large floating structures (VLFS) which dealt with floating platform technology. Shin et al.[4] analyzed motion RAOs (response amplitude operators) in experimental and numerical methods for an OC3-Hywind spar buoy platform which was a model under the IEA Annex 23 Subtask 2 Offshore Code Comparison Collaboration (OC3) project.

However, few studies have been carried out on the fatigue safety of mooring facilities used for the floating platform. This study proposes new concept designs of two different combined renewable platforms. Basic scantlings are determined from the hydrostatic calculations. Hydrodynamic motion analyses are performed to obtain basic motion characteristics such as heave and pitching RAOs. Fully coupled hydrodynamic analyses are then carried out to obtain the time history of each mooring line in the time domain. The tension history of each mooring line is transformed into the peak and valley forms by using the well-known rain-flow cycle counting method. Substituting peak and valley values for the T-N curve (tension-life curve), the final fatigue damage of the mooring line is calculated based on the Palmgren-Miner rule.

\section{Concept design of combined renewable energy platform}

In this paper, two types of ocean renewable energy platforms are considered. The first and second platforms are a combination of wind, wave, and photovoltaic turbines and a combination of wind, current, and photovoltaic turbines, respectively. Hereafter, the former and latter are called Platform 1 and Platform2, respectively. A 5MW wind turbine is mounted on each floating platform.

The water depth is assumed to be $100 \mathrm{~m}$. The incident angle of wave is equal to $90^{\circ}-270^{\circ}$ with a constant increment of $22.5^{\circ}$. For the conservative calculation of motions, wind and current directions are considered to be the same as the wave direction. The fixed values of $10 \mathrm{~m} / \mathrm{s}$ and $2 \mathrm{~m} / \mathrm{s}$ are assigned for wind and current velocities. A modified Pierson-Moskowitz spectrum is used as a wave spectrum. It is assumed that a short term sea state with the largest probability represents the long term sea state and hence the significant wave height and zero crossing period are chosen as $2.5 \mathrm{~m}$ and $8.5 \mathrm{~m} / \mathrm{s}$, respectively, in the wave scatter diagram of the North Atlantic. As a result, the analysis time is two hours, which is known as the minimum duration required to show the stationary and ergodic random process of a wave.

The design draft and ballasting condition are determined from the hydrostatic calculations. The platform is moored by taut mooring lines with high tension, because two platforms resemble the spar type. The length and stiffness of the mooring line are determined in the manner of trial and error. Any nonlinear tensioning effect is not included in the property of the mooring lines.

Platform 1 includes an offshore wind energy turbine, wave energy turbine, and solar panel as shown in Fig. 1(a), while an offshore wind energy turbine, current energy turbine, and solar panel are mounted on Platform 2. 
In the case of Platform1, the wind energy structure is mounted on the center of the triangular floating platform. The solar panel is located on the top of the floating platform. Two types of wave energy generation systems are considered: twenty one auxiliary oscillators and three main wave turbines. Column-type auxiliary wave oscillators are located along the triangular edges and the main horizontal wave energy turbines are installed at the vertex of the triangular platform. Two mooring lines attached at each vertical hull column, thus consequently total six mooring lines, secure the platform against environmental loads.

In the case of Platform2, the wind energy structure is mounted on the center of the triangular floating platform. The solar panel is located in a similar position as that of Platform1, namely it is mounted on the top of the floating platform. Horizontal axis type current turbines are installed at the lower end of each vertical hull column. At a vertex on which the wind turbine tower is mounted, one mooring line is installed and three mooring lines are arranged at the remaining two vertices below the water line of the vertical hull columns.

The mass of each structural component is realized by mass and shell elements. Beam elements representing hull columns and diagonals have their own mass information in terms of beam property and element length, while point mass elements are added at the center of the mass of each structure modeled by shell elements.

For both Platform1 and Platform2, the length and stiffness of each mooring line are $75 \mathrm{~m}$ and $1.5 \mathrm{E} 6$ $\mathrm{N} / \mathrm{m}$, respectively. The expected production capacity of electricity is the 5MW class for both platforms. A summary of mass properties is listed in Table 1. The dimensions of the electricity generation system, floating structure, and mooring lines are also shown in Table 2-6.

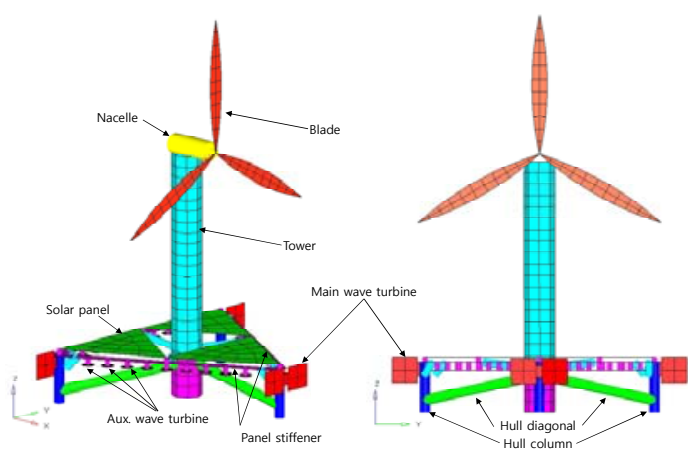

(a) Platform 1

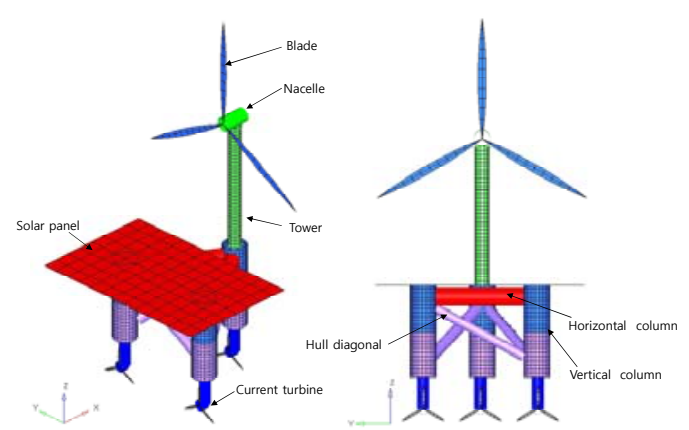

(b) Platform 2

Fig. 1 Structural configuration of combined renewable energy platform

Table 1. Mass property of integrated platform

\begin{tabular}{|l|l|l|}
\hline Item & Platform 1 & Platform 2 \\
\hline Total mass & $3.76 \mathrm{E} 6 \mathrm{~kg}$ & $8.9 \mathrm{E} 6 \mathrm{~kg}$ \\
\hline $\begin{array}{l}\text { Center of mass } \\
\text { about origin }\end{array}$ & $\begin{array}{l}(0.000,0.000,5.137) \\
\mathrm{m}^{*}\end{array}$ & $\begin{array}{l}(-27.493,0.573,8.255) \\
\mathrm{m}\end{array}$ \\
\hline $\begin{array}{l}\text { Mass moment } \\
\text { of inertia (roll } \\
\text { component) }\end{array}$ & $5.332 \mathrm{E} 9 \mathrm{~kg} \cdot \mathrm{m}^{2}$ & $9.395 \mathrm{E} 9 \mathrm{~kg} \cdot \mathrm{m}^{2}$ \\
\hline $\begin{array}{l}\text { Mass moment } \\
\text { of inertia (pitch } \\
\text { component) }\end{array}$ & $5.369 \mathrm{E} 9 \mathrm{~kg} \cdot \mathrm{m}^{2}$ & $6.765 \mathrm{E} 9 \mathrm{~kg} \cdot \mathrm{m}^{2}$ \\
\hline $\begin{array}{l}\text { Mass moment } \\
\text { of inertia (yaw } \\
\text { component) }\end{array}$ & $3.254 \mathrm{E} 9 \mathrm{~kg} \cdot \mathrm{m}^{2}$ & $1.070 \mathrm{E} 10 \mathrm{~kg} \cdot \mathrm{m}^{2}$ \\
\hline
\end{tabular}

* origin is located at the center of triangle and the mean water level

** origin is located at the center of wind tower section and the mean water level 
Table 2. Dimensions of each turbine for Platform

\begin{tabular}{|c|c|c|}
\hline \multirow{7}{*}{$\begin{array}{l}\text { Wind } \\
\text { turbine }\end{array}$} & Turbine capacity & $5 \mathrm{MW}$ \\
\hline & Hub diameter & $8 \mathrm{~m}$ \\
\hline & Tower height & $100 \mathrm{~m}$ \\
\hline & Tower diameter & $12 \mathrm{~m}$ \\
\hline & Tower thickness & $0.02 \mathrm{~m}$ \\
\hline & Blade diameter & $110 \mathrm{~m}$ \\
\hline & Mass of wind turbine & $8.5 \mathrm{E} 4 \mathrm{~kg}$ \\
\hline \multirow{9}{*}{$\begin{array}{l}\text { Wave } \\
\text { turbine }\end{array}$} & Diameter of aux. turbine & $5 \mathrm{~m}$ \\
\hline & Length of aux. turbine & $3 \mathrm{~m}$ \\
\hline & Thickness of aux. turbine & $0.02 \mathrm{~m}$ \\
\hline & Number of aux. turbines & 27 \\
\hline & Width of main turbine & $10 \mathrm{~m}$ \\
\hline & Length of main turbine & $10 \mathrm{~m}$ \\
\hline & Thickness of main turbine & $0.02 \mathrm{~m}$ \\
\hline & Number of main turbines & $3 \mathrm{~m}$ \\
\hline & Mass of wave turbine & $2.6 \mathrm{E} 5 \mathrm{~kg}$ \\
\hline \multirow{3}{*}{$\begin{array}{l}\text { Solar } \\
\text { panel }\end{array}$} & Edge length of panel & $44.3 \mathrm{~m}$ \\
\hline & Thickness of panel & $0.3 \mathrm{~m}$ \\
\hline & Mass of photovoltaic plant & $2.96 \mathrm{E} 6 \mathrm{~kg}$ \\
\hline
\end{tabular}

Table 3. Dimensions of each turbine for Plaform2

\begin{tabular}{|c|l|l|}
\hline \multirow{4}{*}{$\begin{array}{c}\text { Wind } \\
\text { turbine }\end{array}$} & Turbine capacity & $5 \mathrm{MW}$ \\
\cline { 2 - 3 } & Hub diameter & $8 \mathrm{~m}$ \\
\cline { 2 - 3 } & Tower height & $70 \mathrm{~m}$ \\
\cline { 2 - 3 } & Tower diameter & $7 \mathrm{~m}$ \\
\cline { 2 - 3 } & Tower thickness & $20 \mathrm{~mm}$ \\
\cline { 2 - 3 } & Blade diameter & $60 \mathrm{~m}$ \\
\cline { 2 - 3 } & Mass of wind turbine & $2.70 \mathrm{E} 5$ \\
\hline \multirow{4}{*}{$\begin{array}{c}\text { Current } \\
\text { turbine }\end{array}$} & Turbine capacity & $0.2 \mathrm{MW}$ \\
\cline { 2 - 3 } & Number of main turbines & 3 \\
\cline { 2 - 3 } & Length of current generator & $6.12 \mathrm{~m}$ \\
\cline { 2 - 3 } & Blade diameter & $1.2 \mathrm{~m}$ \\
\cline { 2 - 3 } & Mass of wave turbine & $3.5 \mathrm{E} 4$ \\
\hline \multirow{4}{*}{$\begin{array}{l}\text { Solar } \\
\text { panel }\end{array}$} & Edge length of panel & $103 \mathrm{~m}$ \\
\cline { 2 - 3 } & Edge breadth of panel & $67 \mathrm{~m}$ \\
\cline { 2 - 3 } & Thickness of panel & 0.01 \\
\cline { 2 - 3 } & Mass of photovoltaic plant & $5.60 \mathrm{E} 5$ \\
\hline
\end{tabular}

Table 4. Table 4 Dimensions of floating structure for Platform 1

\begin{tabular}{|l|l|}
\hline Diameter of vertical column & $12 \mathrm{~m}$ \\
\hline Length of vertical column & $100 \mathrm{~m}$ \\
\hline Thickness of vertical column & $0.02 \mathrm{~m}$ \\
\hline Diameter of diagonal & $3 \mathrm{~m}$ \\
\hline Length of diagonal & $6.8 \sim 17.8 \mathrm{~m}$ \\
\hline Thickness of diagonal & $0.02 \mathrm{~m}$ \\
\hline Width of panel stiffener & $3.9 \mathrm{~m}$ \\
\hline Thickness of panel stiffener & $0.02 \mathrm{~m}$ \\
\hline Edge length of panel stiffener & $95.8 \mathrm{~m}$ \\
\hline Mass of floating platform & $5.14 \mathrm{E} 5 \mathrm{~kg}$ \\
\hline
\end{tabular}

Table 5. Dimensions of floating structure for Platform2

\begin{tabular}{|l|l|}
\hline Diameter of vertical column & $12 \mathrm{~m}$ \\
\hline Length of vertical column & $46 \mathrm{~m}$ \\
\hline Thickness of vertical column & $20 \mathrm{~mm}$ \\
\hline Diameter of diagonal & $4.9 \mathrm{~m}$ \\
\hline Length of diagonal & $44 \mathrm{~m}$ \\
\hline Thickness of diagonal & $10 \mathrm{~mm}$ \\
\hline Diameter of Horizontal column & $9 \mathrm{~m}$ \\
\hline Length of Horizontal column & $44 \mathrm{~m}$ \\
\hline Thickness of Horizontal column & $20 \mathrm{~mm}$ \\
\hline Mass of Ballast water & $6.2 \mathrm{E} 6$ \\
\hline Mass of floating platform & $1.84 \mathrm{E} 6$ \\
\hline
\end{tabular}

Table 6. Dimensions of mooring line for Platform1 and Platform2

\begin{tabular}{|l|l|l|}
\hline Item & Platform 1 & Platform 2 \\
\hline $\begin{array}{l}\text { Number of } \\
\text { mooring lines }\end{array}$ & 6 & 7 \\
\hline $\begin{array}{l}\text { Length of } \\
\text { mooring line }\end{array}$ & $75 \mathrm{~m}$ & $75 \mathrm{~m}$ \\
\hline $\begin{array}{l}\text { Coordinate of } \\
\text { sea bed from } \\
\text { water line }\end{array}$ & $-100 \mathrm{~m}$ & $-100 \mathrm{~m}$ \\
\hline Mooring type & $\begin{array}{l}\text { Linear line mooring } \\
\text { (strand wire) }\end{array}$ & $\begin{array}{l}\text { Linear line moor- } \\
\text { ing (strand wire) }\end{array}$ \\
\hline Line stiffness & $1.50 \mathrm{E} 6 \mathrm{~N} / \mathrm{m}$ & $1.50 \mathrm{E} 6 \mathrm{~N} / \mathrm{m}$ \\
\hline
\end{tabular}

very important role in keeping the platform stabilized as shown in Figs. 2 (b) and (d). The incident angle of zero is equal to the direction from onshore to offshore as depicted in Figs. 2 (a) and (c). The most critical incident angle seems to be $180^{\circ}$, because the wave approaches with the angle of $180^{\circ}$ as the central figure. 


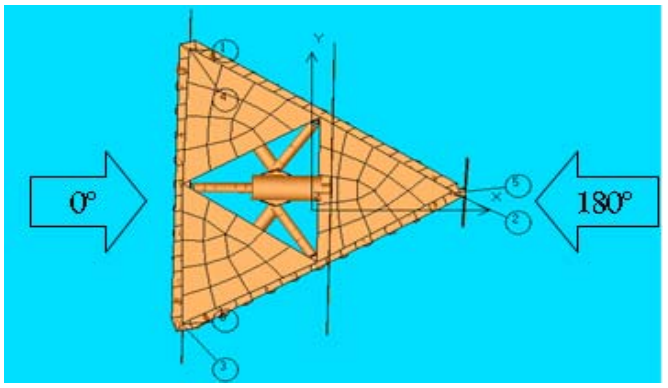

(a) Incident angle of Platform 1

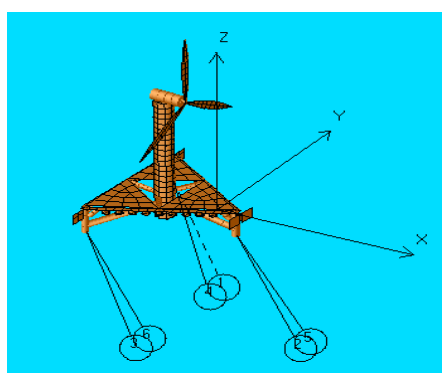

(b) Mooring layout Platform 1

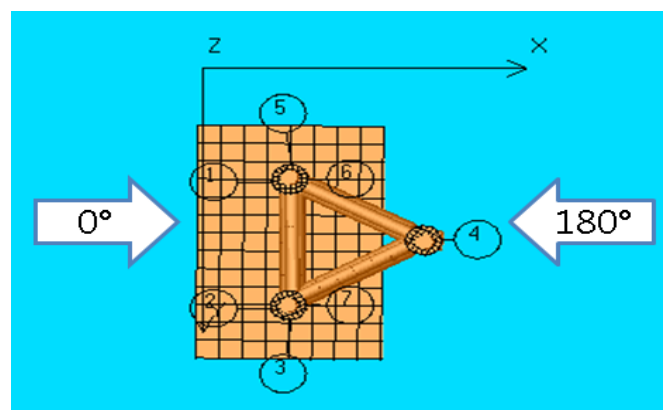

(c) Incident angle of Platform 2

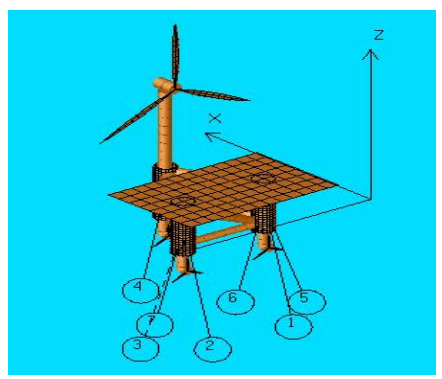

(d) Mooring layout after drift away of platform 2

Fig. 2. Panel model for hydrodynamic analyees
Fig. 3 shows the calculated heave RAOs according to the incident angles of waves. In the case of Platform 1 , the resonance frequency seems to be close to $0.9 \mathrm{rad} / \mathrm{s}$, which is equivalent to approximately 7 sec. Considering that the normal wave period ranges from 5-10 sec, the structural arrangement needs to be changed to avoid continuous resonance with encountering waves. In the case of Platform 2, the resonance frequency is about $0.4 \mathrm{rad} / \mathrm{s}$, which is equivalent to approximately $15.7 \mathrm{sec}$. For this reason, Platform 2 is expected to show better stability under the normal sea condition than Platform1.

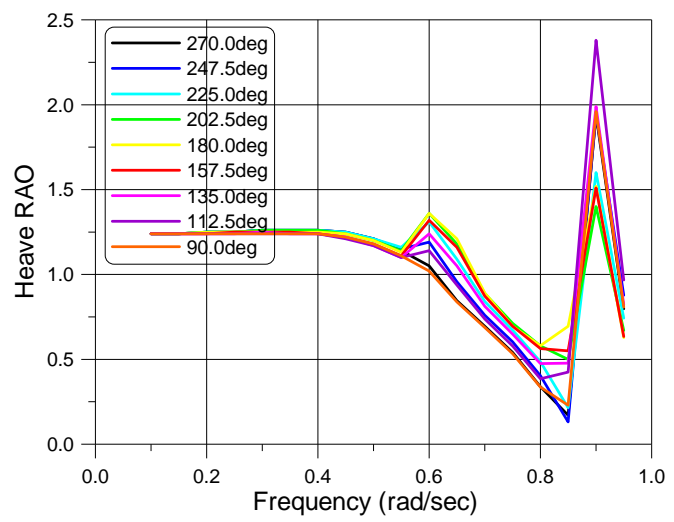

(a) Platform 1

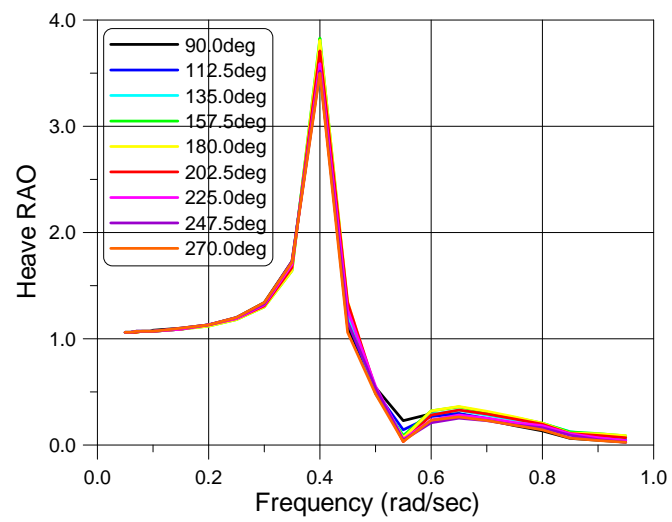

(b) Platform 2

Fig. 3. Heave RAOs

Figs. 4 (a) and (b) show the tension history of the mooring line for Platform 1 and Platform2, respectively. It is expected that mooring line \#2 or \# 5 of 
Platform1 suffers the largest tension history among the mooring lines, because the main angle of wave is $180^{\circ}$. The tension history of mooring line \#5 of Platform1 is shown in Fig. 4(a) according to the incident angle of wave. Mooring line \#4 of Platform 2 experiences the largest tension history among the mooring lines. The tension history of mooring line \#4 of Platform 2 is shown in Fig. 4(b) according to the incident angle of wave. Maximum mean tension occurs at around $180 \mathrm{deg}$, as expected.

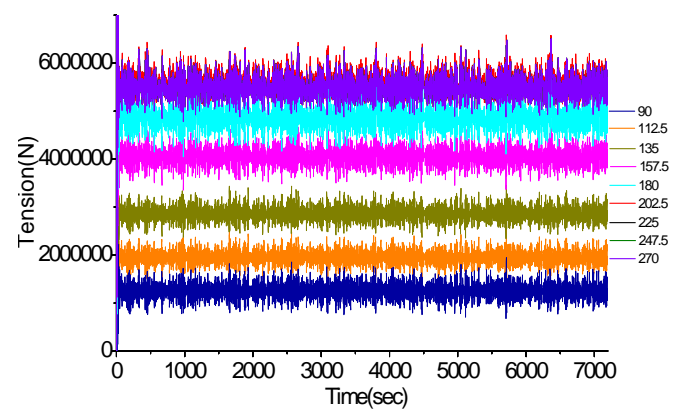

(a) Platform 1

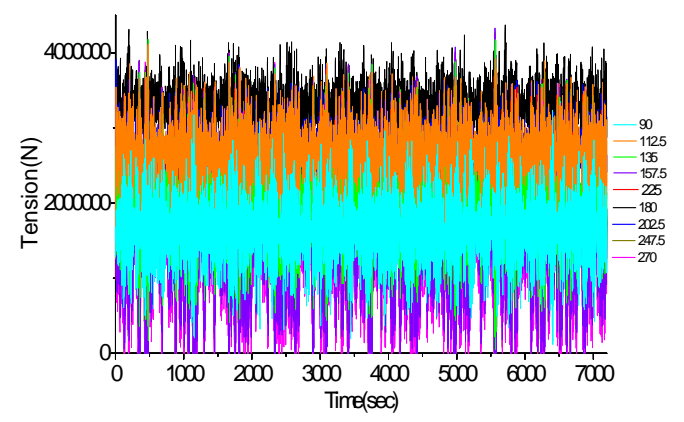

(b) Platform 2

Fig. 4 Tension history of mooring line

\section{Fatigue design}

Since the tension history of a mooring line is random, the counting method is required to identify the number of cycles and tension range. ASTM [5] introduces several types of counting methods, but the rain-flow cycle counting method is known to be the most accurate. Therefore, this study uses the rain-flow cycle counting method to obtain tension ranges. Even though mean stress can be derived from the rain-flow cycle counting method, the effect of mean stress is neglected, because the T-N curves (tension-life curve) of API [6] inherently include the mean stress effect. As delineated in Fig. 5 , API [6] provides T-N curves for various mooring materials such as a socket connector, stud chain, studless chain, spiral strand, and multi-strand. In this paper, the T-N curves of spiral strand and multi strand wires are employed to calculate the fatigue damage of the mooring line.

The ordinate of the T-N curve is $\mathrm{R}$, which is the ratio of the tension range to the reference breaking strength (RBS), hence RBS should be defined. In this paper, the pertinent RBS value is determined based on the fatigue damage calculation. For example, in the case of Platform1, RBS is 4 to 5 , while the RBS of Platform2 is assumed to be 2 and 3 .

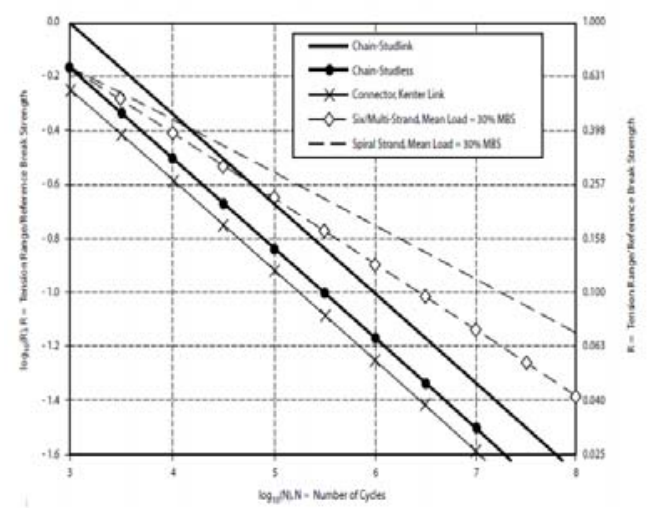

Fig. 5. T-N curve (API [6])

As previously mentioned, in the case of Platform1, the accumulated fatigue damage of each mooring line is calculated when using $R=4$ and 5 . The spiral strand wire with $\mathrm{R}=5$ shows the lowest fatigue damage among the study cases. It is concluded that the assumption of $\mathrm{R}=5$ presents better fatigue strength than that of $R=4$, because the breaking strength of $\mathrm{R}=5$ is stronger than that of $\mathrm{R}=4$. On the other hand, the fact that the T-N curve of the spiral strand wire is located above that of the multi strand wire results in the difference of fatigue damage between the spiral strand and multi strand wires. As expected, the maximum fatigue damage occurs at \#5 mooring line. 
Table 7 Damage table when using spiral strand wire based on $\mathrm{R}=4.0$ (Platform 1)

\begin{tabular}{|l|l|l|l|l|l|l|l|l|l|l|}
\hline Line & $90^{\circ}$ & $112.5^{\circ}$ & $135^{\circ}$ & $157.5^{\circ}$ & $180^{\circ}$ & $202.5^{\circ}$ & $225^{\circ}$ & $247.5^{\circ}$ & $270^{\circ}$ & Dam. \\
\hline$\# 1$ & 0.001 & 0.001 & 0.001 & 0.001 & 0.002 & 0.001 & 0.002 & 0.001 & 0.001 & 0.011 \\
\hline$\# 2$ & 0.043 & 0.056 & 0.049 & 0.083 & 0.077 & 0.086 & 0.074 & 0.044 & 0.018 & 0.059 \\
\hline$\# 3$ & 0.004 & 0.002 & 0.001 & 0.001 & 0.002 & 0.002 & 0.002 & 0.001 & 0.001 & 0.016 \\
\hline$\# 4$ & 0.003 & 0.001 & 0.001 & 0.001 & 0.002 & 0.002 & 0.002 & 0.001 & 0.002 & 0.015 \\
\hline$\# 5$ & 0.026 & 0.038 & 0.043 & 0.083 & 0.088 & 0.111 & 0.111 & 0.088 & 0.047 & 0.634 \\
\hline$\# 6$ & 0.002 & 0.002 & 0.001 & 0.001 & 0.002 & 0.002 & 0.002 & 0.001 & 0.002 & 0.014 \\
\hline
\end{tabular}

Table 8 Damage table when using multi strand wire based on $\mathrm{R}=4.0$ (Platform 1)

\begin{tabular}{|l|l|l|l|l|l|l|l|l|l|l|}
\hline Line & $90^{\circ}$ & $112.5^{\circ}$ & $135^{\circ}$ & $157.5^{\circ}$ & $180^{\circ}$ & $202.5^{\circ}$ & $225^{\circ}$ & $247.5^{\circ}$ & $270^{\circ}$ & Dam. \\
\hline$\# 1$ & 0.008 & 0.001 & 0.003 & 0.004 & 0.010 & 0.009 & 0.011 & 0.007 & 0.006 & 0.060 \\
\hline$\# 2$ & 0.015 & 0.185 & 0.167 & 0.256 & 0.241 & 0.263 & 0.233 & 0.154 & 0.075 & 1.723 \\
\hline$\# 3$ & 0.022 & 0.012 & 0.006 & 0.007 & 0.014 & 0.011 & 0.011 & 0.008 & 0.014 & 0.084 \\
\hline$\# 4$ & 0.017 & 0.007 & 0.003 & 0.004 & 0.010 & 0.010 & 0.011 & 0.008 & 0.014 & 0.084 \\
\hline$\# 5$ & 0.099 & 0.135 & 0.149 & 0.256 & 0.267 & 0.325 & 0.323 & 0.268 & 0.161 & 1.984 \\
\hline$\# 6$ & 0.013 & 0.010 & 0.006 & 0.007 & 0.014 & 0.010 & 0.010 & 0.006 & 0.011 & 0.087 \\
\hline
\end{tabular}

Table 9 Damage table when using spiral strand wire based on $\mathrm{R}=5.0$ (Platform 1)

\begin{tabular}{|l|l|l|l|l|l|l|l|l|l|l|}
\hline Line & $90^{\circ}$ & $112.5^{\circ}$ & $135^{\circ}$ & $157.5^{\circ}$ & $180^{\circ}$ & $202.5^{\circ}$ & $225^{\circ}$ & $247.5^{\circ}$ & $270^{\circ}$ & Dam. \\
\hline$\# 1$ & 0.001 & 0.001 & 0.001 & 0.001 & 0.001 & 0.001 & 0.001 & 0.001 & 0.001 & 0.009 \\
\hline$\# 2$ & 0.014 & 0.018 & 0.016 & 0.027 & 0.025 & 0.027 & 0.024 & 0.014 & 0.006 & 0.170 \\
\hline$\# 3$ & 0.001 & 0.001 & 0.001 & 0.001 & 0.001 & 0.001 & 0.001 & 0.001 & 0.001 & 0.009 \\
\hline$\# 4$ & 0.001 & 0.001 & 0.001 & 0.001 & 0.001 & 0.001 & 0.001 & 0.001 & 0.001 & 0.009 \\
\hline$\# 5$ & 0.008 & 0.012 & 0.014 & 0.027 & 0.028 & 0.036 & 0.036 & 0.028 & 0.015 & 0.204 \\
\hline$\# 6$ & 0.001 & 0.001 & 0.001 & 0.001 & 0.001 & 0.001 & 0.001 & 0.001 & 0.001 & 0.001 \\
\hline
\end{tabular}

Table 10 Damage table when using multi strand wire based on $\mathrm{R}=5.0$ (Platform 1)

\begin{tabular}{|l|l|l|l|l|l|l|l|l|l|l|}
\hline Line & $90^{\circ}$ & $112.5^{\circ}$ & $135^{\circ}$ & $157.5^{\circ}$ & $180^{\circ}$ & $202.5^{\circ}$ & $225^{\circ}$ & $247.5^{\circ}$ & $270^{\circ}$ & Dam. \\
\hline$\# 1$ & 0.003 & 0.001 & 0.001 & 0.002 & 0.004 & 0.004 & 0.004 & 0.003 & 0.003 & 0.024 \\
\hline$\# 2$ & 0.060 & 0.074 & 0.066 & 0.102 & 0.096 & 0.105 & 0.093 & 0.061 & 0.030 & 0.686 \\
\hline$\# 3$ & 0.009 & 0.005 & 0.002 & 0.003 & 0.006 & 0.004 & 0.004 & 0.002 & 0.003 & 0.038 \\
\hline$\# 4$ & 0.007 & 0.003 & 0.001 & 0.001 & 0.004 & 0.004 & 0.005 & 0.003 & 0.006 & 0.033 \\
\hline$\# 5$ & 0.039 & 0.054 & 0.059 & 0.102 & 0.106 & 0.129 & 0.129 & 0.107 & 0.064 & 0.790 \\
\hline$\# 6$ & 0.005 & 0.004 & 0.003 & 0.003 & 0.006 & 0.004 & 0.004 & 0.002 & 0.004 & 0.035 \\
\hline
\end{tabular}

In the case of Platform2, the accumulated fatigue damage of each mooring line is calculated when using $\mathrm{R}=2$ and 3.0. For the same reason as Platform1, the spiral strand wire with $\mathrm{R}=3$ shows the lowest fatigue damage among the study cases. The maximum fatigue damage occurs at \#4 mooring line. 
Table 11 Damage table when using spiral strand wire based on $\mathrm{R}=2.0$ (Platform 2)

\begin{tabular}{|c|c|c|c|c|c|c|c|c|c|c|}
\hline Line & $90^{\circ}$ & $112.5^{\circ}$ & $135^{\circ}$ & $157.5^{\circ}$ & $180^{\circ}$ & $202.5^{\circ}$ & $225^{\circ}$ & $247.5^{\circ}$ & $270^{\circ}$ & Dam. \\
\hline$\# 1$ & 0.015 & 0.011 & 0.036 & 0.018 & 0.024 & 0.023 & 0.020 & 0.019 & 0.009 & 0.176 \\
\hline$\# 2$ & 0.015 & 0.011 & 0.036 & 0.014 & 0.016 & 0.023 & 0.020 & 0.018 & 0.016 & 0.170 \\
\hline$\# 3$ & 0.015 & 0.011 & 0.036 & 0.023 & 0.035 & 0.015 & 0.009 & 0.007 & 0.004 & 0.157 \\
\hline$\# 4$ & 0.015 & 0.011 & 0.036 & 0.088 & 0.102 & 0.085 & 0.121 & 0.014 & 0.016 & 0.489 \\
\hline$\# 5$ & 0.015 & 0.011 & 0.036 & 0.016 & 0.016 & 0.015 & 0.011 & 0.104 & 0.008 & 0.232 \\
\hline$\# 6$ & 0.015 & 0.020 & 0.025 & 0.031 & 0.053 & 0.034 & 0.026 & 0.023 & 0.012 & 0.239 \\
\hline$\# 7$ & 0.019 & 0.020 & 0.025 & 0.031 & 0.053 & 0.034 & 0.026 & 0.023 & 0.012 & 0.242 \\
\hline
\end{tabular}

Table 12 Damage table when using multi strand wire based on R=2.0 (Platform 2)

\begin{tabular}{|c|c|c|c|c|c|c|c|c|c|c|}
\hline Line & $90^{\circ}$ & $112.5^{\circ}$ & $135^{\circ}$ & $157.5^{\circ}$ & $180^{\circ}$ & $202.5^{\circ}$ & $225^{\circ}$ & $247.5^{\circ}$ & $270^{\circ}$ & Dam. \\
\hline$\# 1$ & 0.179 & 0.131 & 0.304 & 0.198 & 0.253 & 0.243 & 0.223 & 0.209 & 0.109 & 1.848 \\
\hline$\# 2$ & 0.179 & 0.131 & 0.304 & 0.158 & 0.169 & 0.243 & 0.212 & 1.140 & 0.141 & 2.677 \\
\hline$\# 3$ & 1.097 & 0.131 & 0.304 & 0.236 & 0.277 & 0.177 & 0.114 & 0.098 & 0.059 & 2.493 \\
\hline$\# 4$ & 1.097 & 0.131 & 0.304 & 0.610 & 0.657 & 0.561 & 0.889 & 0.153 & 0.167 & 4.568 \\
\hline$\# 5$ & 1.097 & 0.131 & 0.304 & 0.180 & 0.187 & 0.171 & 0.132 & 0.383 & 0.096 & 2.680 \\
\hline$\# 6$ & 1.097 & 0.206 & 0.247 & 0.290 & 0.491 & 0.339 & 0.267 & 0.245 & 0.131 & 3.314 \\
\hline$\# 7$ & 1.129 & 0.206 & 0.247 & 0.290 & 0.490 & 0.339 & 0.267 & 0.245 & 0.131 & 3.346 \\
\hline
\end{tabular}

Table 13 Damage table when using spiral strand wire based on $\mathrm{R}=3.0$ (Platform 2)

\begin{tabular}{|c|c|c|c|c|c|c|c|c|c|c|}
\hline Line & $90^{\circ}$ & $112.5^{\circ}$ & $135^{\circ}$ & $157.5^{\circ}$ & $180^{\circ}$ & $202.5^{\circ}$ & $225^{\circ}$ & $247.5^{\circ}$ & $270^{\circ}$ & Dam. \\
\hline$\# 1$ & 0.002 & 0.001 & 0.005 & 0.002 & 0.003 & 0.003 & 0.003 & 0.002 & 0.001 & 0.022 \\
\hline$\# 2$ & 0.002 & 0.001 & 0.005 & 0.002 & 0.002 & 0.003 & 0.003 & 0.002 & 0.002 & 0.022 \\
\hline$\# 3$ & 0.002 & 0.001 & 0.005 & 0.003 & 0.004 & 0.002 & 0.001 & 0.001 & 0.001 & 0.020 \\
\hline$\# 4$ & 0.002 & 0.001 & 0.005 & 0.011 & 0.013 & 0.011 & 0.015 & 0.002 & 0.002 & 0.062 \\
\hline$\# 5$ & 0.002 & 0.001 & 0.005 & 0.002 & 0.002 & 0.002 & 0.001 & 0.013 & 0.001 & 0.029 \\
\hline$\# 6$ & 0.002 & 0.002 & 0.003 & 0.004 & 0.007 & 0.004 & 0.003 & 0.003 & 0.002 & 0.030 \\
\hline$\# 7$ & 0.002 & 0.002 & 0.003 & 0.004 & 0.007 & 0.004 & 0.003 & 0.003 & 0.002 & 0.031 \\
\hline
\end{tabular}

Table 14 Damage table when using multi strand wire based on R=3.0 (Platform 2)

\begin{tabular}{|c|c|c|c|c|c|c|c|c|c|c|}
\hline Line & $90^{\circ}$ & $112.5^{\circ}$ & $135^{\circ}$ & $157.5^{\circ}$ & $180^{\circ}$ & $202.5^{\circ}$ & $225^{\circ}$ & $247.5^{\circ}$ & $270^{\circ}$ & Dam. \\
\hline$\# 1$ & 0.034 & 0.025 & 0.057 & 0.037 & 0.047 & 0.046 & 0.042 & 0.039 & 0.020 & 0.347 \\
\hline$\# 2$ & 0.034 & 0.025 & 0.057 & 0.030 & 0.032 & 0.046 & 0.040 & 0.338 & 0.026 & 0.626 \\
\hline$\# 3$ & 0.325 & 0.025 & 0.057 & 0.044 & 0.052 & 0.033 & 0.021 & 0.018 & 0.011 & 0.587 \\
\hline$\# 4$ & 0.325 & 0.025 & 0.057 & 0.115 & 0.123 & 0.105 & 0.167 & 0.029 & 0.031 & 0.977 \\
\hline$\# 5$ & 0.325 & 0.025 & 0.057 & 0.034 & 0.035 & 0.032 & 0.025 & 0.072 & 0.018 & 0.622 \\
\hline$\# 6$ & 0.325 & 0.039 & 0.046 & 0.054 & 0.092 & 0.064 & 0.050 & 0.046 & 0.025 & 0.741 \\
\hline$\# 7$ & 0.334 & 0.039 & 0.046 & 0.054 & 0.092 & 0.064 & 0.050 & 0.046 & 0.025 & 0.751 \\
\hline
\end{tabular}

\section{Conclusions}

The concept designs of two different floating type combined renewable energy platforms are proposed. Platform1 is a combination of wind turbine, wave turbine, and photovoltaic plant, while
Platform 2 consists of a wind turbine, current turbine, and photovoltaic plant.

Hydrodynamic panel models have been constructed for the two Platforms. Linear dynamic analyses provide motion RAOs from which the heave 
motion of Platform2 provides more stability under the normal ocean condition. From fully coupled time domain analyses, the tension history of each mooring line is obtained.

The tension history is used for the calculation of the fatigue damage of the mooring line. Because the tension history is not regular and is instead random, the rain-flow cycle counting method is introduced to obtain the total number of cycles of line tensions and corresponding tension ranges. The obtained tension data is substituted for the T-N curves provided by API [6] and the fatigue damage is then calculated. The $\mathrm{R}$ value representing the ratio of the tension range to the reference breaking strength should be properly chosen for an economic design with sufficient fatigue strength.

\section{References}

[1] Kim, H.J, Hong, S.W., A Study For integrated Ocean Energy Utilization System, Proceedings of the Korea Committee for Ocean Resources and Engineering Conference Korean Society of Ocean Engineers Semiannual, (2001) pp 88-86.
[2] Ko, K.O., Jung, K.H., Lee, J.S., Yoon, S.B. Park, C.W., Proposal for Applica-tion of the Extra-Large Floating Struc-tures in Order to Develop the Ocean Energy, Journal of Korea institute for Structural Maintenance Inspection, 14(1) (2010) pp 27-32.

[3] Hong, S.Y., Development of Design Technology of Very Large Floating Structures, KORDI Report UCPM0139A-37-2 (2008).

[4] Shin, H., Dam, P.T., Seo, B.C., Kim, J.H., Shin, J.H., Chae, S.H., Rim, C.W., Experimental and Numerical Simulations of the OC3Hywind Floating Offshore Wind Turbine, Proceedings of Annual Spring Meeting of KWEA (2011).

[5] American Society for Testing and Materials (ASTM), ASTM E 1049-85 Standard Practices for Cycle Counting in Fatigue Analysis, (1997).

[6] American Petroleum Institute, API Recommended Practice 2SK Design and Analysis of Station Keeping Systems for Floating Structures, API (2008). 